\title{
Diamond-like carbon coatings in biotribological applications
}

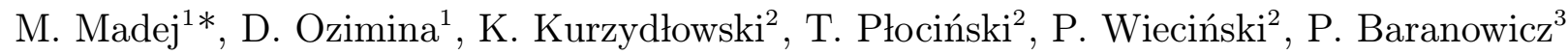 \\ ${ }^{1}$ Kielce University of Technology, 1000-lecia PP 7, 25-314 Kielce, Poland, \\ ${ }^{2}$ Warsaw University of Technology, Wotoska 141, 02-507 Warsaw, Poland \\ ${ }^{3}$ NZOZ Ekstradent, ul. Juliusza Stowackiego 21/1U, 25-365 Kielce, Poland
}

Received 1 December 2014, received in revised form 1 April 2015, accepted 22 September 2015

\begin{abstract}
This paper presents results of the structure analysis and tribological testing of a-C:H type diamond-like carbon (DLC) coatings deposited by Plasma Assisted Chemical Vapour Deposition (PACVD) on CoCrMo specimens. The DLC coatings were selected because of their good biocompatibility and high resistance to corrosion and wear. The surface structure and elemental composition were determined using scanning and transmission electron microscopy. The tribological tests of a cobalt-based alloy disk, or alternatively, a cobalt-based alloy disk with a diamond-like carbon coating, and an alumina ball were determined using a ball-on-disk tribometer under dry friction and lubricated friction conditions. Wear resistance was studied for a pin-on-plate tribological system: a polymeric pin made of ultra-high-molecular-weight polyethylene (UHMWPE) and a CoCrMo plate coated with DLC. The testing was conducted in lubricated friction conditions using Ringer's solution as a lubricant. The test results show that the application of DLC coatings definitely improves the service life of the surface. The DLC coatings were characterized by lower wear resistance and higher corrosion resistance than the CoCrMo alloy.
\end{abstract}

K e y w o r d s: diamond-like carbon, coating, chemical analysis, corrosion, friction

\section{Introduction}

Diamond-like carbon coatings, which are characterized by excellent properties such as very good hardness, low friction coefficient, low tribological wear, chemical passivity, and biocompatibility, are becoming increasingly common in the tool, automotive, food processing and medical industries [1-6]. The superb mechanical and tribological characteristics, high surface smoothness and high biocompatibility make DLC a material highly recommended for biotribological applications [3, 7-12]. DLC coatings deposited on metal elements prove extremely useful in implants, because of their high resistance to wear and other surface properties, such as low surface energy and chemical passivity, which prevent blood coagulation and promote adhesion of osteoblasts, especially in corrosive environments [13-17]. The purpose of this study was to analyze superhard, antiwear DLC coatings deposited by PACVD on a CoCrMo alloy, a material commonly used for a hip endoprosthesis.
Since endoprostheses are vulnerable to various kinds of tribological and corrosive damage, their longterm reliability depends primarily on the materials used for the friction pair $[5,7,9,18]$. The main parts of an artificial joint are a UHMWPE cup and a metal or ceramic ball (head). Metal heads are generally made of cobalt or titanium alloys because of their biocompatibility, and high resistance to corrosion and wear. CoCrMo alloys, which are also common, are characterized by relatively low friction resistance [7, 8, 10, 18]. There are many surface engineering methods that can be used to modify the physical and chemical properties of artificial joints and extend their service life. They include fluorescent processing, laser processing, sol-gel methods, physical vapour deposition, chemical vapour deposition, thermal spraying, electrophoresis, electroplating or a combination of these $[1,13,19-21]$. Each technique will have a different effect on the chemical composition, structure and properties of the surface and, therefore, a different application will be achieved. As attempts to improve the endoprosthesis design and

*Corresponding author: tel.: +48-41-342-4516; fax: +48-41-342-4420; e-mail address: mmadej@tu.kielce.pl 
material by significantly reducing wear has not been successful, investigations are being continued. Recent studies show that DLC coatings have the desired properties to be used as the surface of the endoprosthesis head and stem $[3,5,7,10,12,17]$. DLC coatings were discovered in 1971 by Aisenberg and Chabot, who obtained hydrogen-free amorphous carbon while cooling a low-energy carbon ion beam in argon $[5,13,16,22$, 23 . The discovery proved to be ground-breaking, and the technologies of their preparation are still being developed. Amorphous carbon may consist of $s p^{3}, s p^{2}$, and even $s p^{1}$ bonds. Amorphous carbon materials exhibit large differences in structure. The ratio of $s p^{2}$ to $s p^{3}$ bonds is the major factor defining the properties of amorphous materials $[1,6,13,15]$. Amorphous carbon with significant amounts of $s p^{3}$ hybridized carbon atoms is known as DLC.

\section{Material and methods}

\subsection{Substrate and coating materials}

In this study, tests were conducted on a CoCrMo alloy, commercially known as Biodur CCM PLUS, which is characterized by high mechanical strength, corrosive resistance, and wear resistance. The alloy was produced by powder metallurgy using the Vacuum Induction Melting (VIM) method. The analysis was focused on a-C:H coatings produced by Plasma Assisted Chemical Vapour Deposition (PACVD) at $<250^{\circ} \mathrm{C}$. The coatings were commercially produced as Oerlikon Balzers BALINIT DLC. They were characterized by the following parameters:

- hardness of $1900 \mathrm{HV}$,

- $10 \%$ atomic hydrogen content,

- $30 \%$ of the $s p^{3}$ bonds [3].

Another material tested was UHMWPE. Its molecular weight determined with the viscometric method ranges from 2 to 10 million $\mathrm{g} \mathrm{mol}^{-1}$. The properties of UHMWPE make the material suitable for biomedical applications. The physical properties of the UHMWPE tested, with the commercial name of Chirulen, are described in Refs. [24, 25].

\subsection{Chemical composition - GDOES analysis}

The Glow Discharge Optical Emission Spectrometry (GDOES) analysis was carried out using a Horiba Jobin Yvon spectrometer with a glow discharge powered by a Radio Frequency (RF) source. The spectrometer anode is a grounded copper tube, and the sample is used as the cathode. The GDOES spectrometer can be used to analyze the volume and the surface. It is destructive testing because a crater of $4 \mathrm{~mm}$ in diameter is created in a sample. Volume analysis is used to determine the quantitative composition of a sample, i.e. the concentration of various elements generally expressed as weight percentage. Before testing, it is necessary to calibrate the instrument using reference standards. Surface analysis is used to determine the qualitative or quantitative distribution of elements beyond the tested surface and show changes in voltage signals for each element in real time. The quantitative surface analysis shows changes in the elemental composition of the sample, expressed as atomic or weight percentage.

\subsection{Scanning and transmission electron microscopy}

The specimens - the CoCrMo alloy and the CoCrMo alloy coated with DLC - were prepared for the analysis by applying a Hitachi FB2100 focused ion beam (FIB) system. The cross-sections were observed using a Hitachi SU 70 scanning electron microscope equipped with a field emission gun of the Schottky type. The specimens were inclined at an angle of $40^{\circ}$, which was a maximum angle for specimens of this size. As a result, the thickness in the images was lower than in reality. The actual dimensions are obtained at an angle of inclination of $90^{\circ}$. When describing the results, we use real dimensions, and we include the degree of inclination of the specimen. The TEM observation was performed using a Hitachi s5500 High-Resolution Scanning Electron Microscope equipped with a field emission electron gun operating at a maximum accelerating voltage of $30 \mathrm{keV}$. The analysis was conducted in the SE mode, which is a standard mode of SEM, and in the STEM mode, using a beam passing through the specimen. The chemical composition was determined using energy dispersive $\mathrm{X}$-ray spectroscopy (EDS).

\subsection{Tribological tests}

The most popular system for assessing the tribological properties of materials in contact is a ball-ondisk configuration. A T-01M tester was used to study the behaviour of a-C:H coatings in contact with an alumina ball under the following conditions:

- type of motion: sliding,

- contact geometry: ball-on-disk (point contact),

- $\mathrm{Al}_{2} \mathrm{O}_{3}$ ball $10 \mathrm{~mm}$ in diameter,

- wear track radius: $18 \mathrm{~mm}$,

- load: $P=10 \mathrm{~N}$,

- sliding velocity: $v=0.1 \mathrm{~m} \mathrm{~s}^{-1}$,

- friction displacement: $s=1000 \mathrm{~m}$,

- lubricating fluid: none or RINGER's solution,

- relative moisture: $55 \pm 5 \%$,

- ambient temperature: $T_{0}=22 \pm 1{ }^{\circ} \mathrm{C}$.

The wear testing was also performed using a pinon-plate (T-17) device according to the standard listed as Ref. [26]. The coefficient of friction and the wear 
rate were determined in the function of the number of cycles. The T-17 system is designed to perform tribological analysis of different pairs of materials with surfaces in sliding contact moving in a reciprocating motion. The two friction systems tested were: a UHMWPE pin and a CoCrMo plate, and a UHMWPE pin and a CoCrMo plate with a DLC coating. The following parameters were used to test these metalpolymer systems:

- type of motion: sliding-reciprocating,

- contact geometry: pin-on-plate (conformal),

- UHMWPE: pin $9 \mathrm{~mm}$ in diameter,

- test duration/number of cycles: 1,000,000 s/ 1,000,000;

- amplitude: $12.7 \mathrm{~mm}$,

- frequency: $1 \mathrm{~Hz}$,

- average sliding rate: $50 \mathrm{~mm} \mathrm{~s}^{-1}$,

- load: $225 \mathrm{~N}$,

- lubricating fluid: RINGER's solution,

- temperature of the fluid during testing: $37 \pm 1{ }^{\circ} \mathrm{C}$.

The values of the friction coefficient and the wear intensity determined in all the tribological tests were presented as averages over the entire duration of the test.

\subsection{Corrosive properties}

The electrochemical corrosion tests were carried out at $20^{\circ} \mathrm{C}$ in a $3 \%$ aqueous $\mathrm{NaCl}$ solution. A threeelectrode system was used for the measurements. DLC coatings or CoCrMo alloys were used as working electrodes with an area of $0.390 \mathrm{~cm}^{2}$. The counter electrode with $s=1.5 \mathrm{~cm}^{2}$ was a platinum metal sheet. A saturated calomel electrode (SCE) was used as a reference electrode. Electrode polarization measurements were performed using an ATLAS 0531 electrochemical test kit. A vessel with an opening in a side wall was used for the tests. Voltammetric characteristics were obtained for the range of from $-800 \mathrm{mV}$ to +1600 $\mathrm{mV}$, at a sampling frequency of $1 \mathrm{mV}$ and a sampling rate of change of the potential of $100 \mathrm{mV} \mathrm{min}{ }^{-1}$. The stationary potential, $E_{\text {cor }}$, was measured 20 min after immersion of the sample in a $3 \% \mathrm{NaCl}$ solution.

Cathodic and anodic reactions take place simultaneously close to $E_{\text {cor, }}$ and if both occur at the activation overpotential, then the dependence of the current density on the electrode potential is described by the Butler-Volmer equation:

$$
\begin{aligned}
j & =j_{\text {cor }}\left\{\exp \left[2.303\left(E-E_{\text {cor }}\right) / b_{\mathrm{a}}\right]-\right. \\
& \left.-\exp \left[-2.303\left(E-E_{\text {cor }}\right) / b_{\mathrm{c}}\right]\right\}
\end{aligned}
$$

where $b_{\mathrm{a}}$ and $b_{\mathrm{c}}$ are Tafel coefficients for the anodic and cathodic reaction, respectively, and $j_{\text {cor }}$ is corrosion current density.

The values of $j_{\text {cor }}, b_{\mathrm{a}}$, and $b_{\mathrm{c}}$ were determined using the iterative method of matching the parame-

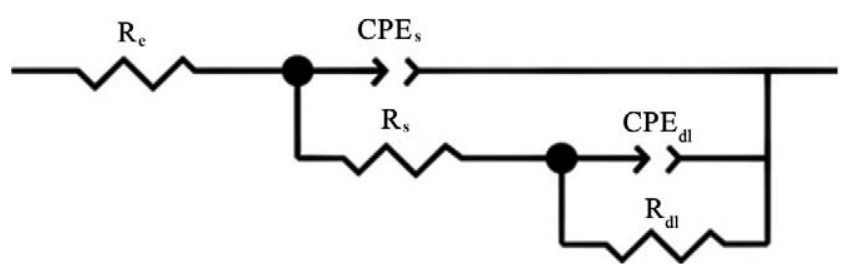

Fig. 1. Equivalent circuit model: $\mathrm{CPE}_{\mathrm{dl}}$ is constant phase element describing the double layer, $\mathrm{CPE}_{\mathrm{s}}$ is constant phase element describing the surface layer, $R_{\mathrm{e}}$ is the resistance of the electrolyte, $R_{\mathrm{d} 1}$ is the resistance of charge transfer through the double layer, $R_{\mathrm{S}}$ is the resistance of the electrolyte in the pores of the surface layer.

ters of Eq. (1) to the current-voltage data in the socalled non-Tafel area. The values of the polarization resistance, $R_{\mathrm{p}}$, were calculated using the Stern-Geary equation:

$$
j_{\text {cor }}=\frac{b_{\mathrm{a}} b_{\mathrm{c}}}{2.303\left(b_{\mathrm{a}}+b_{\mathrm{c}}\right)} \frac{1}{R_{\mathrm{p}}} .
$$

Electrochemical impedance spectroscopy is particularly useful for the study of corrosion mechanism and adsorption on the electrode surface. Methods for determining the corrosion rate are based on the charge transfer resistance, $R_{\mathrm{t}}$. $R_{\mathrm{t}}$ allows for the calculation of the corrosion current density according to the equation:

$$
j_{\text {cor }}=\frac{b_{\mathrm{a}} b_{\mathrm{c}}}{2.303\left(b_{\mathrm{a}}+b_{\mathrm{c}}\right)} \frac{1}{R_{\mathrm{t}}} .
$$

If the values of $b_{\mathrm{a}}$ and $b_{\mathrm{c}}$ are slightly affected by the experiment conditions, it can be assumed that the values of $j_{\text {cor }}$ are inversely proportional to $R_{\mathrm{t}}$. Measurements were carried out in a three-electrode system, with an open circuit potential, at a frequency of $10,000 \mathrm{~Hz}$ to $0.01 \mathrm{~Hz}$ and a signal amplitude of $10 \mathrm{mV}$, recording five measurement points per 10-fold change. Impedance data recording was initiated $20 \mathrm{~min}$ after the immersion of the test electrode in a $3 \%$ solution at $20^{\circ} \mathrm{C}$. The most common way to analyze impedance spectra is to select an equivalent electrical circuit, showing a similar dependence of impedance on frequency $[4,27]$. In the study, the data was analyzed using an equivalent circuit model of the electrode shown in Fig. 1, in which the capacity is replaced by a Constant-Phase-Element (CPE) used in the description of the impedance curves (Nyquist plots). The $\mathrm{CPE}$ admittance is expressed by the equation:

$$
Y_{\mathrm{CPE}}=Y_{\mathrm{o}}(j \omega)^{n}
$$

where $\omega$ is angular frequency, $Y_{\mathrm{o}}$ is absolute CPE admittance, $n=\alpha /(\pi / 2)$ is an exponent, and $\alpha$ is CPE phase angle.

The CPE describes an ideal capacitor for $n=1$ and an ideal resistor for $n=0$. If $n=0.5$, it can be 

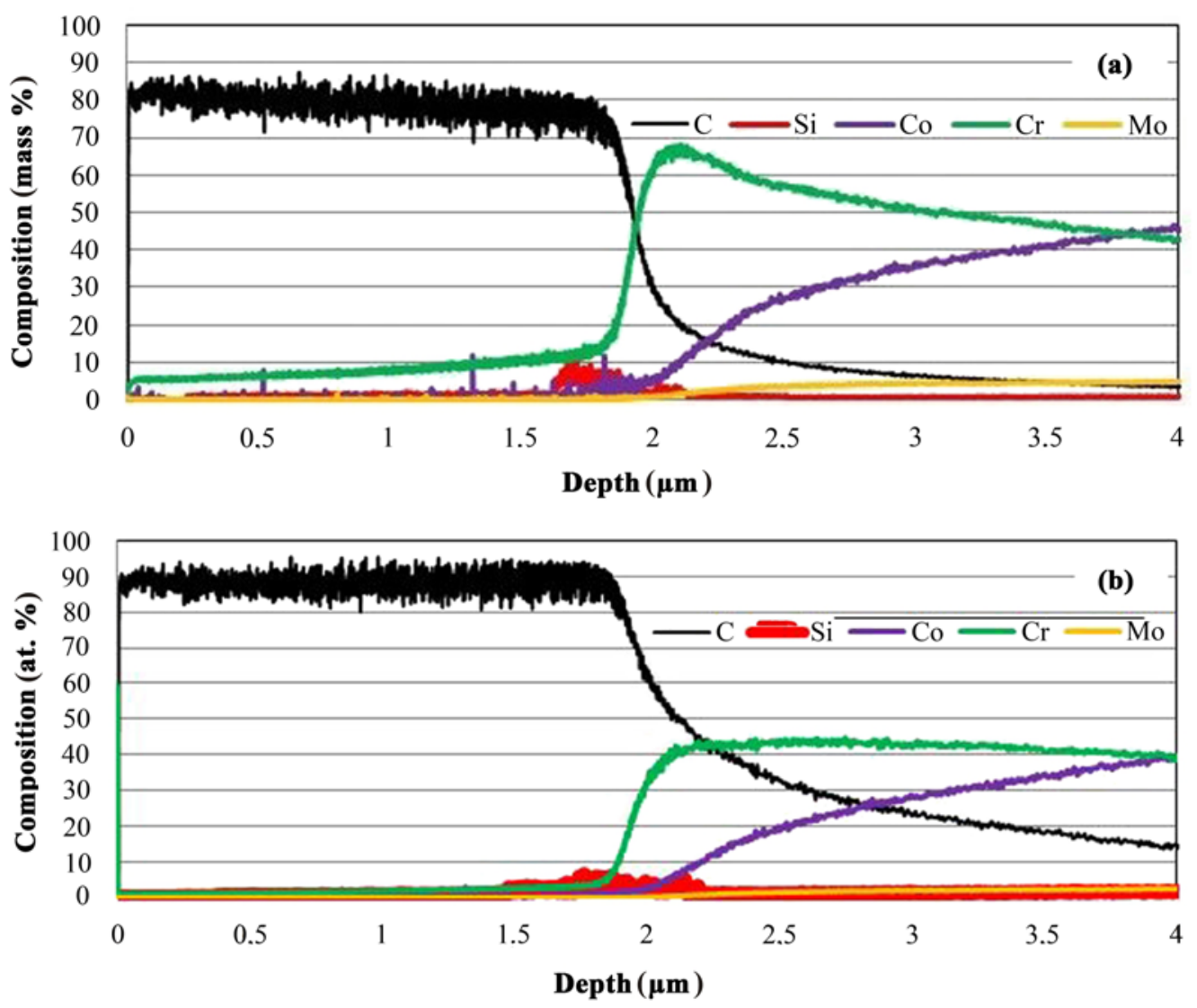

Fig. 2. Distribution of elements from the surface down into the a-C:H coating: (a) weight percentage, (b) atomic percentage.

assumed that in the electrode process there is resistance associated with the diffusion of reactants. The value of $\alpha$ reflects the deviation from the ideal dielectric characteristics; it indirectly defines the degree of enhancement of the electrode surface. If the value is less than 1 , then the surface is more enhanced.

The analysis and matching of the experimental data to the response of a mathematical model are usually based on the method of least squares. In the present study, the ZView (Scribner Associates Inc.) impedance data analysis program was used. The results of the impedance measurements were presented in the form of Nyquist plots showing the dependence of the imaginary component of the impedance $Z_{y}$ on the real component $Z_{x}$, and Bode plots, showing the change of log impedance modulus and phase angle $\theta$ as a function of frequency $f$. Least-squares matching included error estimation to obtain $\chi^{2}<0.05$.

$$
\chi^{2}=\sum_{i=1}^{n} \frac{\left|\mathrm{Z}_{x}^{\mathrm{exp}}-\mathrm{Z}_{x}^{\mathrm{cal}}\right|^{2}-\left|\mathrm{Z}_{y}^{\mathrm{exp}}-\mathrm{Z}_{y}^{\mathrm{cal}}\right|^{2}}{\left|Z^{\exp }\right|^{2}}
$$

where $Z_{x}^{\exp }, Z_{y}^{\exp }$, and $\left|Z^{\exp }\right|$ are experimental data for the real and imaginary components of impedance and impedance modulus, $Z_{x}^{\text {cal }}$ and $Z_{y}^{\text {cal }}$ are data calculated using the adopted equivalent electrode model. As a result of matching, the parameters of the electrode equivalent circuit are obtained in the form of:

- constant-phase elements: $\mathrm{CPE}_{\mathrm{dl}}, \mathrm{CPE}_{\mathrm{s}}$,

- resistance: $R_{\mathrm{e}}, R_{\mathrm{dl}}, R_{\mathrm{s}}$,

- exponents: $n_{\mathrm{dl}}$ and $n_{\mathrm{s}}$.

Assessing the corrosive properties of the samples, we took account of the values of $j_{\text {cor }}, R_{\mathrm{s}}, R_{\mathrm{dl}}$ and the range limits of the passive state potentials.

\section{Results and discussion}

\subsection{GDOES analysis}

GDOES was used to analyze the chemical composition of the specimens. The quantitative analysis showed the weight and atomic percentage of each element. The results of the GDOES analysis are illustrated in Fig. 2 for each coating separately.

The chemical composition of the coating varies with depth. As can be seen, there is chromium and silicon transitional layer between the CoCrMo alloy substrate and the proper DLC surface layer. Its aim is to improve the adhesion of the coating to the substrate. 


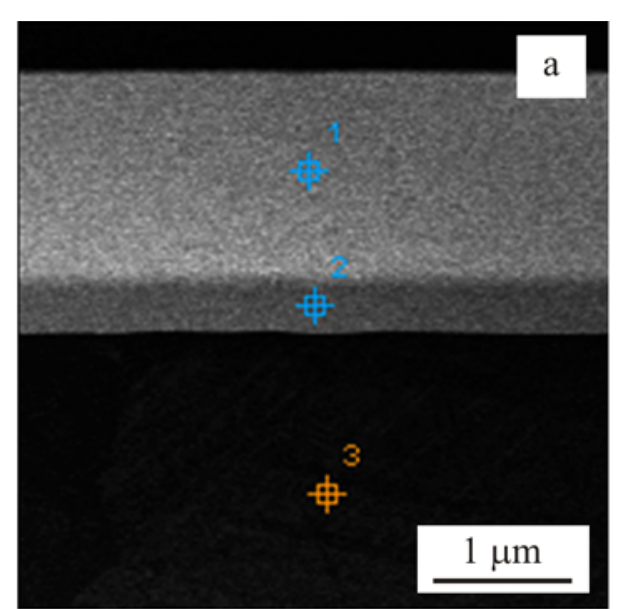

(b)
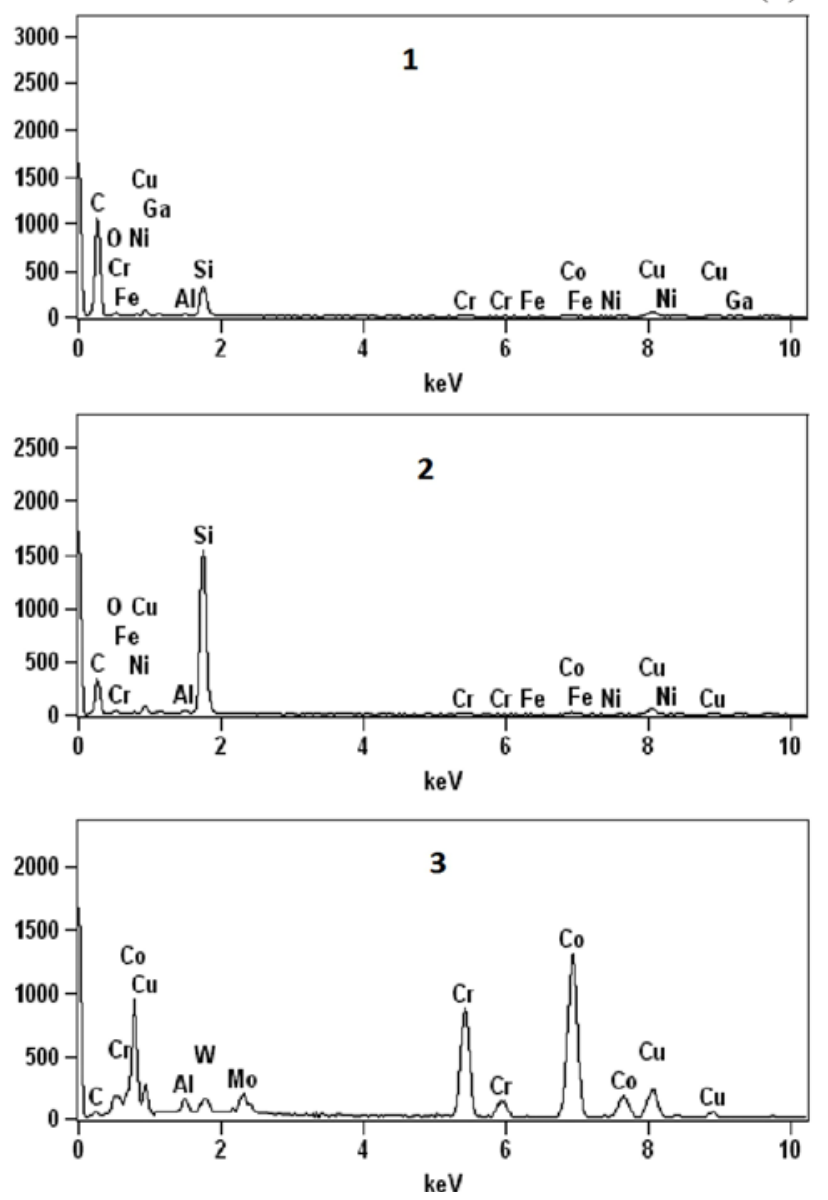

Fig. 3. (a) Points of the chemical composition analysis for the substrate and the coating; (b) characteristic X-ray spectra.

\subsection{Scanning and transmission electron microscopy}

The DLC-coated specimens were observed with a scanning electron microscope. The point microanalysis was used to determine the elemental composition

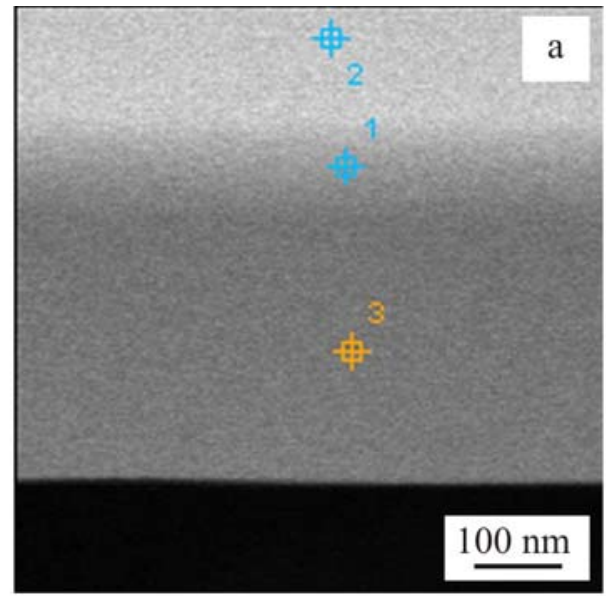

(b)
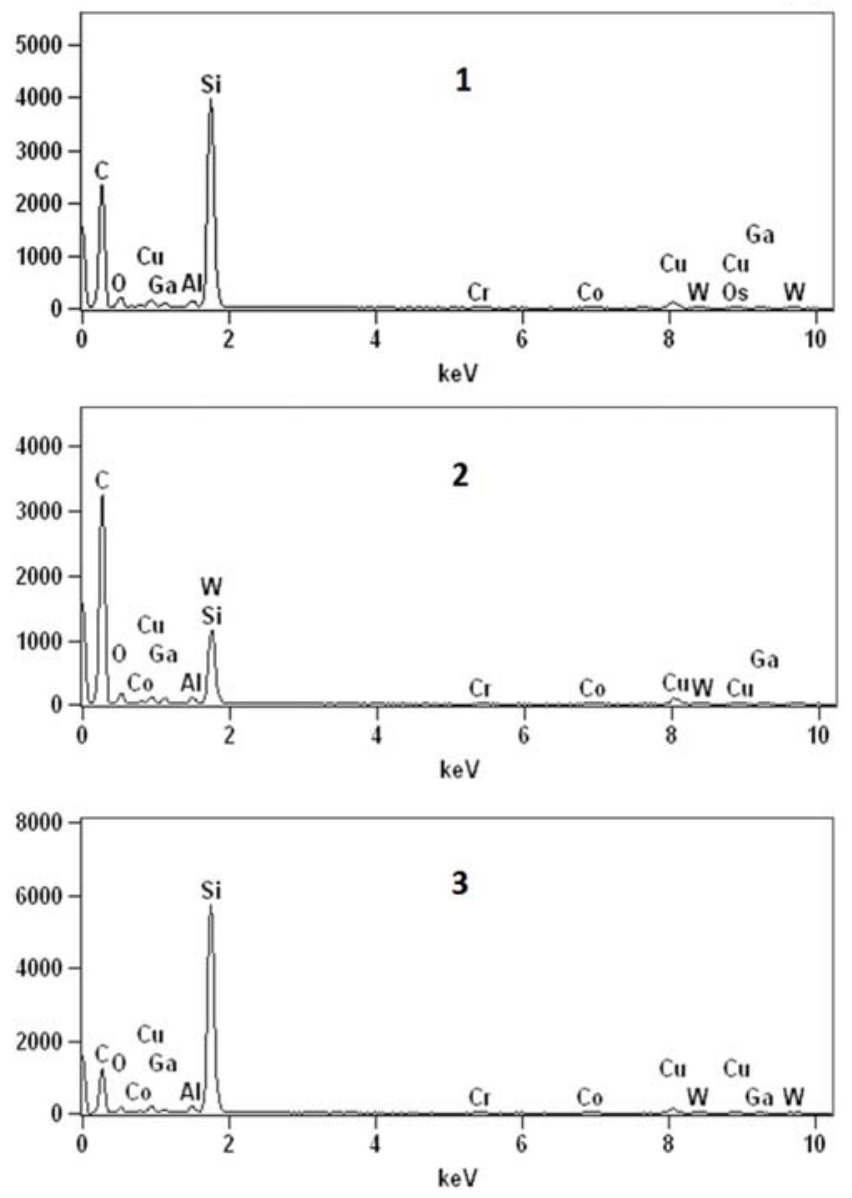

Fig. 4. (a) Points of the chemical composition analysis for the transitional layer; (b) characteristic X-ray spectra.

quantitatively. The results of the chemical composition analysis for the transitional layer and the substrate are presented in Figs. 3, 4 and Tables 1, 2.

The quantitative analysis performed with a scanning electron microscope equipped with an energydispersive spectrometer (EDS) was not suitable to de- 
Table 1. Chemical composition of the substrate and the coating (at.\%)

\begin{tabular}{lcccccc}
\hline & C-K & O-K & Si-K & Cr-K & Co-K & Mo-L \\
\hline Point 1 & 99.09 & 0.00 & 0.82 & 0.03 & 0.06 & 0.00 \\
Point 2 & 88.36 & 5.85 & 5.59 & 0.07 & 0.13 & 0.00 \\
Point 3 & 58.61 & 0.00 & 0.00 & 12.19 & 27.33 & 1.88 \\
\hline
\end{tabular}

Table 2. Chemical composition of the transitional layer (at.\%)

\begin{tabular}{llllll}
\hline & C-K & O-K & Si-K & Cr-K & Co-K \\
\hline Point 1 & 93.53 & 3.84 & 2.55 & 0.03 & 0.04 \\
Point 2 & 98.45 & 0.69 & 0.80 & 0.02 & 0.04 \\
Point 3 & 89.11 & 5.19 & 5.54 & 0.05 & 0.11 \\
\hline
\end{tabular}

termine the content of carbon. However, it was possible to draw conclusions about the chemical composition of the transitional layer. The outer layer is the proper DLC coating containing mainly carbon while the transitional layer lying directly on the substrate contains silicon (partially oxidized). The quantitative analysis of the transitional layer, which did not show the content of carbon, indicated the presence of $\mathrm{Si}$ and $\mathrm{O}_{2}$ and traced amounts of $\mathrm{Cr}$ and $\mathrm{Co}$. The transitional layer contained both carbon and silicon.

\subsection{Wear testing}

The tribological properties were analyzed using a ball-on-disk system. The tribological tests were performed under dry sliding friction conditions and lubricated friction conditions (with Ringer's solution as the lubricant) for the substrate material and the DLC coatings in the configurations with a ceramic $\mathrm{Al}_{2} \mathrm{O}_{3}$ ball. The test results were plotted to show the changes in the coefficient of friction $\mu$, and the wear of the specimens for each friction pair. It is important that the same parameters be used during the tests to determine the tribological characteristics of the materials, especially for dry friction conditions. This is because an uncoated surface with no passive layer exhibits high adsorption capacity and reactivity with the surroundings. The results of the tribological tests, i.e. the coefficient of friction $\mu$ and wear, are represented graphically in Figs. 5a, b, respectively.

For specimens without a coating, which were tested at constant load and velocity, the average value of the coefficient of friction reached 0.49 under dry friction conditions and 0.32 under lubricated friction conditions. The wear ranged $0-14.3 \mu \mathrm{m}$ and $0-6.4 \mu \mathrm{m}$, respectively, with the friction displacements being $1000 \mathrm{~m}$.

From the diagrams, it is evident that the coefficients of friction and wear are lower for the a-C:H coatings than for the CoCrMo alloys. For specimens with the a-C:H coating, the coefficient of friction
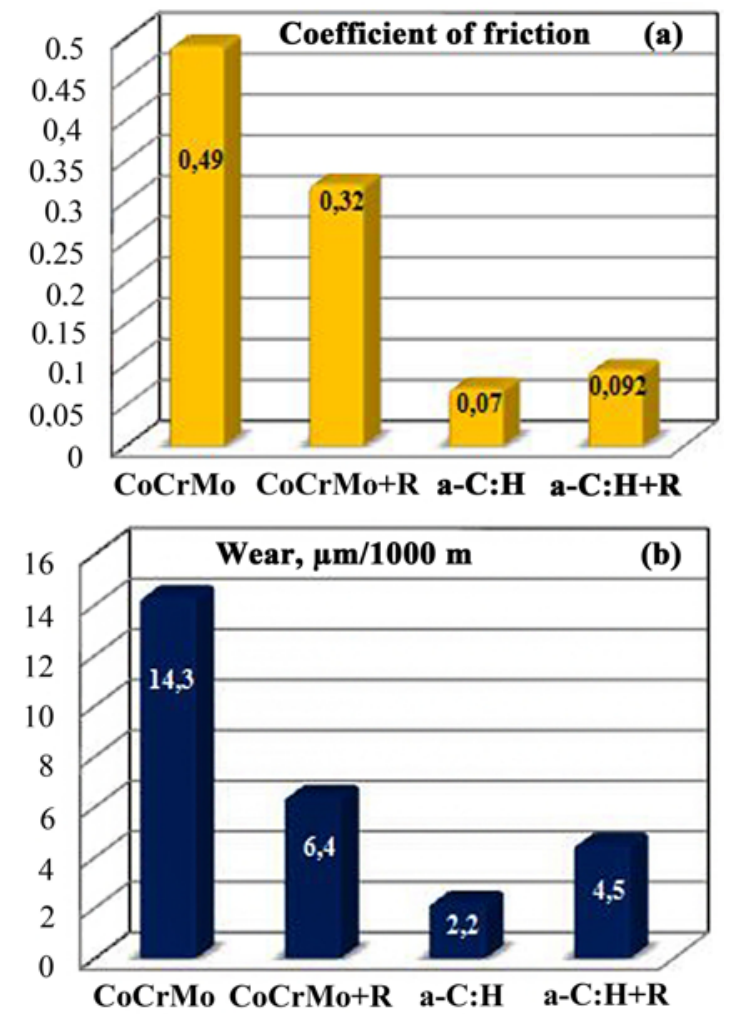

Fig. 5. Coefficients of friction and wear registered for a system of an $\mathrm{Al}_{2} \mathrm{O}_{3}$ ceramic ball and a CoCrMo specimen with and without an a-C:H coating.

reached 0.07 under dry friction conditions and 0.092 under lubricated friction conditions. The wear ranged from 0 to $2.2 \mu \mathrm{m}$ under dry friction conditions and from 0 to $4.5 \mu \mathrm{m}$ under lubricated friction conditions. The friction coefficient and the wear of DLC coatings tested with Ringer's solution show higher values than those tested under dry conditions. In the case of the CoCrMo coating, the findings are opposite; low friction and wear are shown when Ringer's solution was used. Further research is required to study the be- 


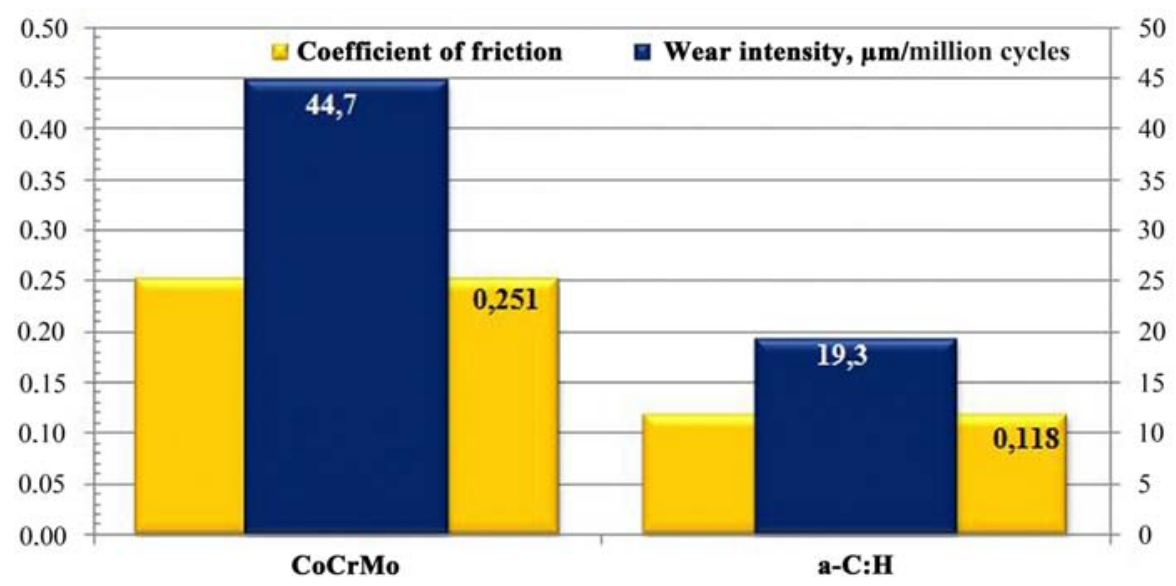

Fig. 6. Coefficient of friction and wear intensity vs. the number of cycles for the UHMWPE-CoCrMo and the UHMWPEa-C:H coating systems.

haviour and determine the adsorption reaction interaction on the surface of the friction pairs.

The tribological tests were performed using a pin-on-plate configuration operating in the reciprocating motion. The friction pair comprised a stationary pin made of UHMWPE and a mobile plate made of CoCrMo, or alternatively, CoCrMo coated with DLC. The characteristics of the coefficient of friction and wear intensity for $1,000,000$ cycles are presented in Fig. 6 .

As can be seen from Fig. 6, the friction coefficient reported for the CoCrMo alloy was higher than that for the DLC coating. The average coefficient of friction, $\mu$, for the CoCrMo and UHMWPE system was 0.251 while for the a-C:H and UHMWPE system it was 0.118 . Figure 6 demonstrates that the wear intensity is considerably lower for the DLC coating than for the CoCrMo alloy. Analyzing the results, we can see that the a-C:H-type DLC coating exhibited better tribological properties than the CoCrMo alloy at the same pre-determined test parameters.

The coating with a total thickness of about $1.88 \mu \mathrm{m}$ consisted of two main layers: a transitional layer lying directly on the substrate, the thickness of which was about $325 \mathrm{~nm}$, and an outer layer with a thickness of approx. $1.454 \mu \mathrm{m}$. In between these, there is a boundary region with a thickness of about $100 \mathrm{~nm}$. The DLC coating with a total thickness of about $2.10 \mu \mathrm{m}$ comprised three fundamental areas: a light area, lying directly on the surface, a dark area, being the outer part of the coating, and a transitional area including elongated "needles" extending from the light area (Fig. 7a). The two extreme areas - dark and light - are phases with different chemical compositions (Figs. 3, 4).

After tribological testing, the total thickness of the coating decreased to $1.51 \mu \mathrm{m}$ (Fig. 7b). The coating morphology also changed. There was no transitional area between the light and dark phases, with needles
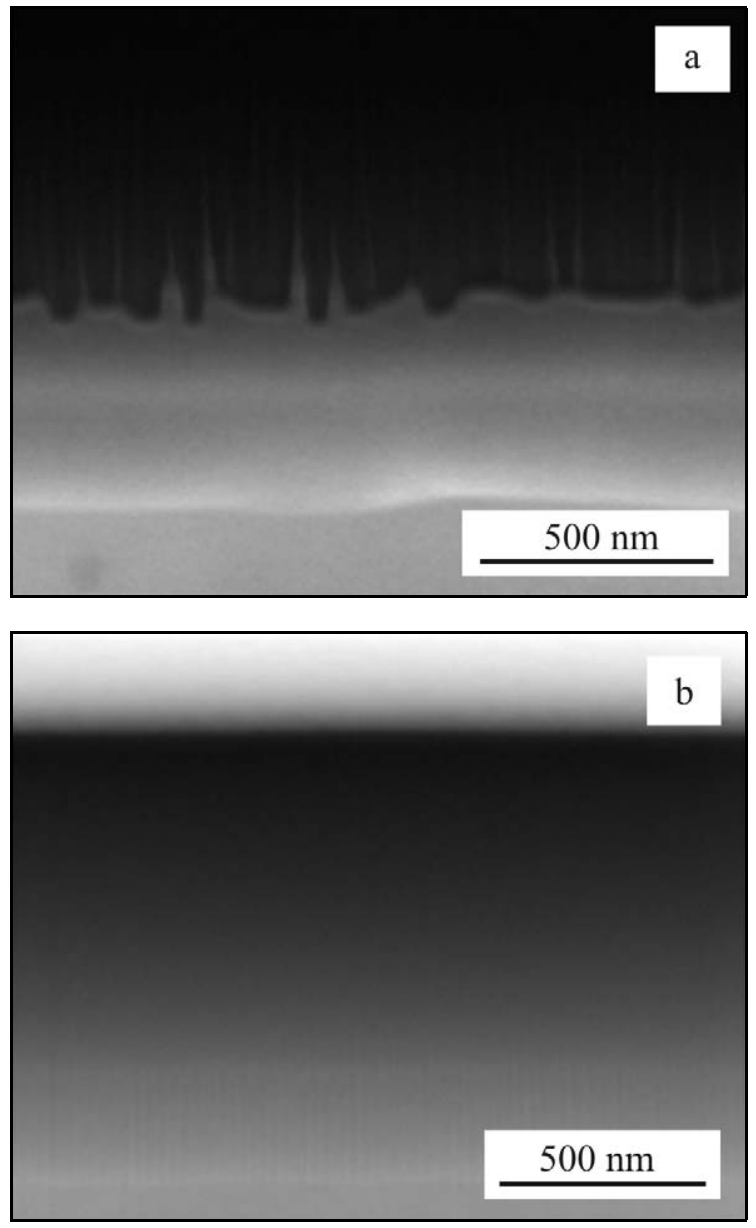

Fig. 7. SEM images of the cross-sections of the a-C:H coating a) before and b) after the tribological tests.

extending from the light phase. Moreover, the contrast between the light and dark phases was much smaller than in the coating. The thickness of the light phase after abrasion was $0.4 \mu \mathrm{m}$, which means it was 

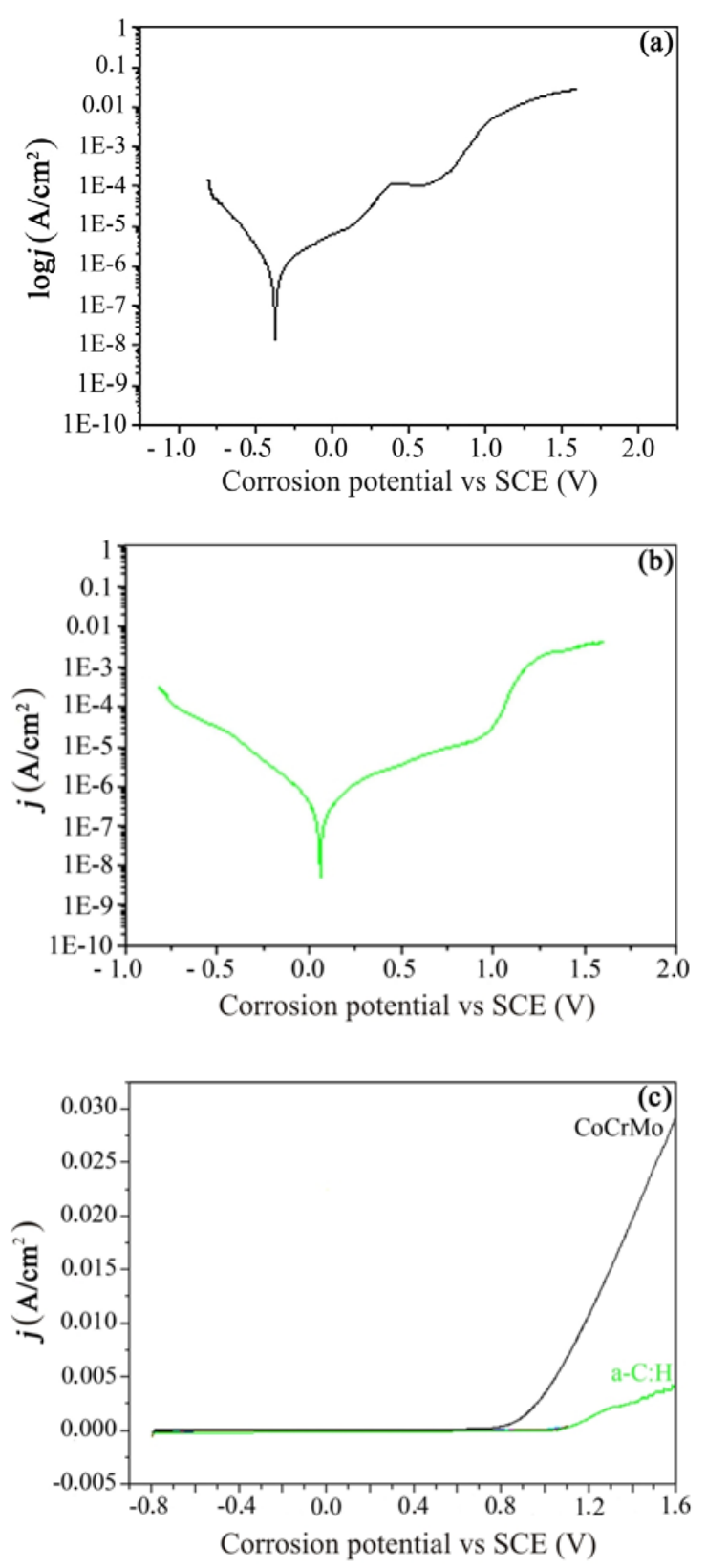

Fig. 8. Voltammetric characteristics obtained for (a) the CoCrMo alloy and (b) the a-C:H coating, immersed in a $3 \% \mathrm{NaCl}$ solution at $20^{\circ} \mathrm{C}$, and (c) potentiodynamic polarization curves.

$0.2 \mu \mathrm{m}$ smaller than that of the coating. The thickness of the dark phase was 1.1 , which is $0.2 \mu \mathrm{m}$ more than in the coating. The difference suggests that no clear transitional area was observed in that specimen. The area was incorporated into the thickness of the dark phase. The differences reported before and after tribological tests shown in Fig. 7 suggest that during friction with lubrication Ringer's solution diffusion-reaction transformation of the coating occurs. As a result of this transformation, DLC coatings should be characterized by good anticorrosion parameters.

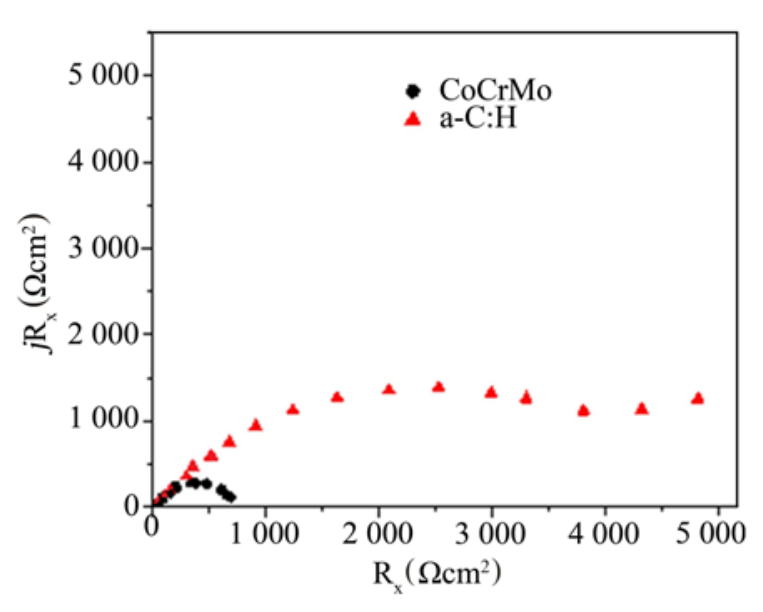

Fig. 9. Nyquist diagrams for the CoCrMo alloy and a-C:H coating.

\subsection{Corrosive properties}

The electrochemical studies included DC polarization tests. It was crucial to determine the corrosion current density and register the corrosive characteristics of both the corroding CoCrMo electrode with an area of $0.390 \mathrm{~cm}^{2}$ and the diamond-coated electrode. The current-voltage characteristics of the CoCrMo electrodes with and without DLC coatings indicate the active-passive behaviour of the coatings (Fig. 8).

The corrosion resistance was higher for the coated rather than uncoated specimens. The results summarized in Table 3 show that the corrosion current density of CoCrMo is more than 3.5 times higher than that of the a-C:H coating. The values of the Tafel coefficients, $b_{\mathrm{a}}$ and $b_{\mathrm{c}}$, indicate the cathodic control of the corrosion mechanisms.

Figure 8 and Table 3 show that samples coated with a-C:H had lower corrosion current density and corrosion potential but higher polarization resistance. The corrosion rate expressed by corrosion current density is considerably lower for the CoCrMo substrate than for the a-C:H coating.

The results were verified using the method of electrochemical impedance spectroscopy. Impedance data were analyzed using the equivalent circuit model (Fig. 1). The matching results are shown in Table 4.

The impedance curves of the CoCrMo alloy samples and the impedance curves for the DLC coatings are similar in shape (Fig. 9). The arches are fragments of flattened semi-circles with different diameters, depending on the material. The results of the impedance measurements over a wide frequency range show that the corrosion resistance characterized by $R_{\mathrm{S}}$ is significantly higher for the DLC coating than for the CoCrMo substrate. 
Table 3. Results of the polarization curve analysis

\begin{tabular}{lccccc}
\hline $\begin{array}{l}\text { Sample } \\
\text { material }\end{array}$ & $\begin{array}{c}\text { Corrosion } \\
\text { current density } \\
J_{\text {cor }}\left(\mathrm{A} \mathrm{m}^{-2}\right)\end{array}$ & $\begin{array}{c}\text { Tafel coefficient } \\
\text { for the anode } \\
\text { reaction } \\
b_{\mathrm{a}}(\mathrm{V})\end{array}$ & $\begin{array}{c}\text { Tafel coefficient } \\
\text { for the cathode } \\
\text { reaction } \\
b_{\mathrm{c}}(\mathrm{V})\end{array}$ & $\begin{array}{c}\text { Corrosion } \\
\text { potential } \\
E_{\text {cor }}(\mathrm{V})\end{array}$ & $\begin{array}{c}\text { Polarization } \\
\text { resistance } \\
R_{\mathrm{p}}\left(\Omega \mathrm{m}^{2}\right)\end{array}$ \\
\hline Substrate & $1.33 \times 10^{-2}$ & 0.56 & 0.26 & -0.37 & 5,88 \\
a-C:H & $0.38 \times 10^{-2}$ & 0.42 & 0.23 & 0.61 & 17,52 \\
\hline
\end{tabular}

Table 4. Equivalent circuit parameters

\begin{tabular}{lcc}
\hline Equivalent circuit parameters & CoCrMo alloy & a-C:H coating \\
\hline$R_{\mathrm{e}}\left(\Omega \mathrm{m}^{2}\right)$ & 0.001517 & 0.002021 \\
$\mathrm{CPE}_{\mathrm{l}}\left(\mathrm{Fs}^{n-1} \mathrm{~m}^{-2}\right)$ & 0.847 & 0.115 \\
$n_{\mathrm{l}}$ & 0.52107 & 0.49405 \\
$R_{\mathrm{l}}\left(\Omega \mathrm{m}^{2}\right)$ & 0.001127 & 0.002334 \\
$\mathrm{CPE}_{\mathrm{dl}}\left(\mathrm{Fs}^{n-1} \mathrm{~m}^{-2}\right)$ & 0.365 & 0.516 \\
$n_{\mathrm{dl}}\left(\Omega \mathrm{m}^{2}\right)$ & 0.97518 & 0.88901 \\
$R_{\mathrm{d} l}$ & 8.7542 & 13.5313 \\
\hline
\end{tabular}

\section{Conclusions}

Recent studies concerning the endoprosthesis design have focused on the improvement in the wear and corrosion resistance of biomaterials. With DLC coatings becoming increasingly popular, researchers are investigating their various applications including biotribological systems. This paper has analyzed the behaviour of a-C:H type DLC coatings deposited by PACVD on CoCrMo. The chemical composition analysis shows that the structure of the coatings contributes to their antiwear properties. The SEM analysis reveals that the DLC coatings have a homogeneous structure. The results of the electrochemical corrosion tests, graphically represented by voltammetric and impedance characteristics, indicate that the corrosion resistance of the DLC coatings is significantly higher than that of the CoCrMo alloy, with the latter being commonly used in endoprosthesis heads and stems. Friction pairs with DLC-coated elements show better tribological properties than those with uncoated CoCrMo elements when operating under dry friction conditions or lubricated friction conditions with Ringer's solution used as the lubricant. The good tribological properties, i.e. lower values of the coefficient of friction and wear, are attributable to favourable tribochemical interactions taking place on the surfaces in contact. Despite being thin (within dimensional tolerance limits), the DLC coatings offer perfect protection against tribological and corrosive wear. From this study, it is evident that DLC-coated CoCrMo has suitable characteristics to be used in the medical industry, for example, for elements of an artificial human hip joint prosthesis. DLC coatings de- posited on elements for biotribological systems have to meet substantially higher quality requirements than industrially applied DLC coatings. The desirable properties including high adhesion, high mechanical stability are not discussed in this paper; the issues will be studied in the future.

\section{References}

[1] Donnet, C., Erdemir, A. (Eds.): Tribology of Diamond-Like Carbon Films. Fundamentals and Applications. New York, Springer 2008.

[2] Gangopadhyay, A., Sinha, K., Uy, D., McWatt, D., Zdrodowski, R., Simko, S.: Tribology Transactions, 54, 2010, p. 104. doi:10.1080/10402004.2010.525693

[3] Madej, M.: Properties of Tribological Systems with Diamond-Like Carbon Coatings. Monography 46. Kielce, Kielce University of Technology 2013.

[4] Madej, M., Marczewska-Boczkowska, K., Ozimina, D.: Przemysł Chemiczny (Chemical Review), 93, 2014, p. 500. (in Polish).

[5] Eason, R. (Ed.): Pulsed Laser Deposition of Thin Films: Applications-LEad Growth of Functional Materials. New York, Wiley 2007. doi:10.1002/0470052120

[6] Robertson, J.: Materials Science and Engineering R., 37, 2002, p. 129. doi:10.1016/S0927-796X(02)00005-0

[7] Carapeto, A., Serro, A., Nunes, B., Martins, M., Todorovic, S., Duarte, M., André, V., Colaco, R., Saramago, B.: Surf. \& Coat. Tech., 204, 2010, p. 3451. doi:10.1016/j.surfcoat.2010.04.022

[8] Dernaley, G., Arps, J. H.: Surf. \& Coat. Tech., 200, 2005, p. 2518. doi:10.1016/j.surfcoat.2005.07.077

[9] Madej, M., Ozimina, D., Piwoński, I., Kisielewska, A.: Kovove Mater., 41, 2012, p. 297.

[10] Roy, R. K., Lee, K. R.: Journal Biomed. Mater. Res. B, 83, 2007, p. 72 . doi:10.1002/jbm.b.30768 
[11] Thorwarth, G., Falub, C., Muller, U., Weisse, B., Voisard, C., Tobler, M., Hauert, R.: Acta Biomaterialia, 6, 2010, p. 2335. doi:10.1016/j.actbio.2009.12.019

[12] Thomson, L., Law, F., Rushton, N., Franks, J.: Biomaterials, 12, 1991, p. 37. doi:10.1016/0142-9612(91)90129-X

[13] Bosman, M., Keast, V. J., Watanabe, M., McCulloch, D. G., Shakerzadeh, M., Teo, E., Tay, B.: Carbon, 47, 2009, p. 94. doi:10.1016/j.carbon.2008.09.033

[14] Holmberg, K., Ronkainen, H., Matthews, M.: Ceramics International, 26, 2000, p. 787. doi:10.1016/S0272-8842(00)00015-8

[15] Madej, M., Ozimina, D., Kurzydłowski, K., Płociński, T., Wieciński, P., Styp-Rekowski, M.: Journal of Machine Engineering, 2, 2012, p. 53.

[16] Marciano, F., Bonetti, L., Santos, L., Da-Silva, N., Corat, E., Trava-Airoldi, V.: Diamond and Related Materials, 18, 2009, p. 1010. doi:10.1016/j.diamond.2009.02.014

[17] Shi, B., Ajayi, B., Fenske, G., Erdemir, A., Liang, H.: Wear, 255, 2003, p. 1015. doi:10.1016/S0043-1648(03)00276-X

[18] González-Mora, V. A., Hoffmann, M., Stroosnijder, R., Gil, F. J.: Materials Science and Engineering C, 29, 2009, p. 153. doi:10.1016/j.msec.2008.06.006
[19] Madej, M.: Wear, 317, 2014, p. 179. doi:10.1016/j.wear.2014.05.008

[20] Michalczewski, R., Piekoszewski, W., Szczerek, M., Tuszyński, W.: Tribology International, 42, 2009, p. 554. doi:10.1016/j.triboint.2008.05.001

[21] Zdravecká, E., Tiainen, V., Konttinen, Y., Franta, L., Vojs, M., Marton, M., Ondáč, M., Tkáčová, J.: Vacuum, 86, 2012, p. 675 . doi:10.1016/j.vacuum.2011.07.011

[22] Aisenberg, S., Chabot, R.: Journal of Applied Physics, 42, 1971, p. 2953. doi:10.1063/1.1660654

[23] Zhiqiang, F., Jian, S., Chengbiao, W., Wei, Z., Wen. Y., Zhijian, P., Xiang, Y., Songsheng, L., Mingjiang, D.: Vacuum, 94, 2013, p. 14. doi:10.1016/j.vacuum.2013.01.006

[24] Kurtz, S.: UHMWPE Biomaterials Handbook. Burlington, Elsevier 2009.

[25] Li, S.: Operative Techniques in Orthopedics, 11, 2001, p. 288. doi:10.1016/S1048-6666(01)80044-6

[26] ASTM 732-82. Reciprocating Pin-on-Flat Evaluation of Friction and Wear Properties of Polymeric Materials for Use in Total Joint Prostheses.

[27] Scendo, M., Trela, J., Radek, N.: Corrosion Reviews, 30, 2012, p. 33. doi:10.1515/corrrev-2011-0039 